\title{
FISCAL STIMULATION OF HUMAN CAPITAL AND RESULTANT ECONOMIC GroWth in SOUTh Africa
}

\author{
GERHARDUS VAN ZYL \\ Department of Economics \& Econometrics \\ University of Johannesburg \\ South Africa \\ LUMENGO BONGA-BONGA \\ Department of Economics E Econometrics \\ University of Johannesburg \\ South Africa \\ Correspondence to: Gerhardus van Zyl \\ e-mail: hardusvz@uj.ac.za
}

\begin{abstract}
The aim of the paper is to econometrically model the relationship between national fiscal expenditure on human capital (national education and training expenditure) and the efficiency of the human resource base in stimulating economic growth. Data on government spending was collected from the South African Reserve Bank (SARB) quarterly bulletins (for the period 1979 - 2006). A functional form of a production function, namely the constant elasticity of substitution modelling (CES modelling), was employed to test the stated hypothesis. The results of the study indicate that fiscal stimulus of human capital in South Africa does not translate into high technological change and ultimately higher economic growth rates.
\end{abstract}

Keywords: human capital, CES econometric modelling, endogenous growth theory, fiscal stimulus, economic growth

\begin{abstract}
The aim of the paper is to assess the relationship between fiscal expenditure on human capital (education and training) and the efficiency of the human resource base in stimulating economic growth. The null-hypothesis of this study is that increased fiscal stimulation of human capital in the form of increased national spending on education and training should improve the efficiency of the human resource base in the economy and ultimately result in higher levels of economic growth.
\end{abstract}

The paper will propose that some structures be followed in order to measure the relationship between the fiscal stimulus of human capital (education and training expenditure) and economic growth in South Africa. Firstly, it is proposed that the correct functional form of the production function in South Africa be chosen for modelling the impact on the efficiency of the human resource base and economic growth. Secondly, the total factor productivity will be derived from the CES) functional form of the production function by using the Kalman filter technique. The reason why the CES functional format was chosen is that this format is a general form of the production function that can take the form of different production functions. The Kalman filter technique enabled the researchers to model the unobserved variables (in this study it was the technological change). Lastly, the relationship between the fiscal stimulus of human capital and technological change will be assessed by using the Granger causality test. The Granger causality test was simply applied in order to determine the relationship between the technological change and spending on education and training.

The theoretical background underpinning the relationship between fiscal stimulus of human capital and economic growth will be discussed in terms of the endogenous growth theory. The endogenous growth theory provides a scope for analysing the connection between fiscal policy and economic growth in general and is discussed in the next section.

\section{Endogenous growth theory}

According to the endogenous growth model, the pace of technological change should have an economic explanation and factors such as the efficiency of human capital, education and training attainment and expenditure, to mention but a few, should affect technological change and therefore economic growth (Gylfason, 1999).

In the endogenous growth theory the path of economic growth is dictated by the level of technological change, which level is determined mostly by the efficiency of human capital, level of research and development (hereafter referred to as $R \& D$ ), as well as learning by doing. The concept of endogenous growth is aligned to the fact that technological change is not exogenous (as stipulated by the neoclassical theory), but rather endogenous as it depends on the above factors.

According to Alfonso and Werner (2005), public spending, especially education and training spending, can drive R\&D to a more efficient level than one that would prevail in a pure market scenario and will therefore constitute an impetus for economic growth. Temple (2000) remarked that the effectiveness of direct subsidies or tax credit for R\&D may be enhanced by complementary education and training policies, aimed at improving or subsidising the supply of research inputs.

The model of endogenous growth provides the very important insight that knowledge and skills are the key input in the creation of new ideas. This provides the most scientifically plausible justification for perceiving the fiscal stimulus of human capital as a central determinant of economic growth rates over a long time interval. The impact of the fiscal stimulus of human capital on economic growth is then seen as a longterm instead of a short-term relationship, suggesting that the consequences of a change in education and training policy will emerge fully only in the long term (Weil, 2005).

In view of these realities, the researcher can infer that the fiscal stimulus of human capital could affect technological change and ultimately economic growth. This is the path followed in this paper when the relationship between the fiscal stimulus of human capital (national budget spending on education 
and training) and economic growth is measured, and this constitutes the first research objective. For the second research objective the Granger causality test will be used to measure this particular relationship (more specifically the relationship between technological change and economic growth).

This study specifically uses the national government budget for education and training expenditure as a proxy for the fiscal stimulus of human capital when measuring the impact on economic growth. The first reason for the above is that the marginal product on education and training expenditure (which defines how the change in education and training expenditure would affect the change in output) should be an appropriate indicator of the real return on education and training. Secondly, if assessment of the relationship between government education and training expenditure and economic growth shows government education and training expenditure does not cause a change in output, it may lead to the conclusion that government education and training expenditure does not translate into efficient human capital formation or innovation. Human capital development, innovation and skills accumulation are important ingredients for technological change, and therefore for economic growth according to the endogenous growth model.

\section{The prediction model and research method}

To model and estimate the production function from the CES production function there was a need to linearise the function in order to estimate the parameters of the model econometrically.

Two different approaches have been used to estimate the parameters of the CES production function: the direct and indirect approaches. With the direct method of estimation, the CES function is directly estimated from its non-linear form. Ripatti and Vilmunen (2001), for example, estimated a CES specification directly using non-linear, co-integration techniques. They nevertheless made some implicit assumptions with regard to unobservable variables such as the technological change level and implicitly restricted the number of common trends and co-integration vectors.

This paper adopted the indirect method of estimation as proposed by Nerlove (1967). Nerlove's two-step estimation consists of establishing the ratio of two marginal productivity conditions under perfect competition to estimate the elasticity of substitution in the first step. In the second step the elasticity of substitution obtained from the first step is used to compile a new series that is used to estimate the technological change coefficients and the scale of production. The linearised form is therefore:

$\log Q_{t}=\log A_{t}+\mu \log V_{t}$

Or $\log Q_{t}=\log A_{0}+\lambda t+\mu \log V_{t}$

As the second-step estimation applies the Kalman filter technique, equation 1 was used to capture the changing nature of $\mathrm{A}_{\mathrm{t}}$.

This paper extends Nerlove's estimation techniques by using Hicks' assumption of neutral technology (it is a kind of technology that is exogenous, impacted on by other variables) in the production function specification. The paper also estimates the long-term relationship between the variables in the first-step estimation by the introduction of the Autoregressive Distributed Lag (hereafter referred to as ARDL) co-integration technique, and then applies the Kalman filter technique to estimate the unobservable variables and the scale of production parameters in the second step of estimation. The ARDL is a logical way to test the relationship between variables by incorporating the lag effect.

The ARDL co-integration approach, as proposed by Pesaran, Shin and Smith (1999), was applied to determine the long- term relationship of the variables included in the first-step linearisation, namely capital-labour ratio $\left(\log \frac{K}{L}\right)$ and the ratio of the price of capital and labour $\left(\log \left(\frac{P_{k}}{P_{t}}\right)\right)$. As shown in Appendix A, the former is integrated of order one, while the latter is integrated of order zero. This supported the use of the ARDL co-integration technique.

The Kalman filter technique was applied for the second-step estimation that provided the final estimation of the South African aggregate production function. The paper supports the view that technological change $\left(A_{t}\right)$ is not only seen as an unobserved component in the production function, but also as time varying (Harvey, 1989). Moreover, the researcher is of the opinion that the degree of the scale of production is not static for a long period as this can vary with the level of technological change. These considerations lead to the application of a technique that provides for unobservable variables and timevarying parameters, namely the Kalman filter technique.

\section{RESULTS}

Three different models were used in this study. The first model refers to the first step of Nerlove's linearisation of the CES function where the relationship between capital-labour ratio and the price of labour and capital is estimated. As explained above the aim is to obtain the value of the elasticity of substitution to be used in step two. The second model was used to estimate the production function. This refers to the second step in Nerlove's linearisation process. From this second estimation the technological change parameters were identified as timevarying coefficients. The last step aimed to assess whether the fiscal stimulus of human capital in South Africa affected technological change and therefore economic growth.

The data series used in this study consisted of the average capital labour ratio (LNRATIOCAL), the ratio of average wages and the prime overdraft rates (LNWAGINT) as the proxy of the price of labour by the price of capital, logarithm of the gross domestic product (LNGDP), the capital stock $(\mathrm{K})$ and the employment level (L). These data series were obtained from various quarterly bulletins published by the South African Reserve Bank, as well as from the time series publication by Statistics South Africa.

\section{The estimation of the relationship between the capital- labour ratio and the ratio of capital-labour price}

Using the above data, the ARDL co-integration technique was applied to the equation $\log \left(\frac{K}{L}\right)=-\left(\frac{1}{\rho+1}\right) \log \left(\frac{\delta}{1-\delta}\right)-\left(\frac{1}{\rho+1}\right) \log \left(\frac{P_{k}}{P_{L}}\right)$ where the long-term relationship was to be determined between the average capital-labour ratio and the ratio of capital and labour price. The unit root test for stationarity of the two series provided mixed results: While there was strong evidence in favour of the existence of unit root for the LNWAGINT series, LNRATIOCAL provided mixed results when different criteria selection for lags were applied. Following the ARDL co-integration technique as introduced by Pesaran et al. (1999), this fact does not hinder the existence of the long-term relationship between the two series.

As far as the lag selection (p) is concerned, this study employed the lag selection that minimises the Akaike Information Criteria (hereafter referred to as AIC). They are criteria used to select the best model. This revealed that a one-period lag was an appropriate selection for the model.

The time series plot LNRATIOCAL revealed a structural break around 1986. This was a result of 1986 being the period of South Africa's national state of emergency characterised by a huge outflow of capital. The ARDL representation therefore introduced the dummy variable (DAM) in its specification at that specific date. 
TABLE 1

ARDL co-integration relationship between LNWAGINT and LNRATIOCAL

\begin{tabular}{lcccc}
\hline $\begin{array}{l}\text { DEPENDENT VARIABLE: DLNRATIOCAL } \\
\text { Method: Least Squares }\end{array}$ & \multicolumn{5}{l}{. } \\
\cline { 2 - 5 } Variables & Coefficients & $\begin{array}{l}\text { Standard } \\
\text { Error }\end{array}$ & t-Statistic & Probability \\
\hline C & 1.171304 & 0.273326 & 4.285375 & 0.0003 \\
DLNRATIOCAL(-1) & 0.193363 & 0.163575 & 1.182106 & 0.2487 \\
DLNWAGINT & -0.000203 & 0.007988 & -0.025454 & 0.9799 \\
DLNWAGINT(-1) & -0.004217 & 0.007819 & -0.539280 & 0.5947 \\
LNRATIOCAL(-1) & -0.101799 & 0.023918 & -4.256128 & 0.0003 \\
LNWAGINT(-1) & -0.011208 & 0.003882 & -2.887142 & 0.0081 \\
DAM (Correction term) & -0.009866 & 0.005610 & -1.758715 & 0.0914 \\
R-squared & 0.928614 & Mean dependent var & 0.006918 \\
Adjusted R-squared & 0.910768 & S.D. dependent var & 0.025833 \\
S.E. of regression & 0.007717 & Akaike info criterion & -6.695142 \\
Sum squared residual & 0.001429 & Schwarz criterion & -6.371338 \\
Log likelihood & 110.7747 & F-statistic & 52.03370 \\
Durbin-Watson stat & 2.195255 & Prob (F-statistic) & 0.000000 \\
\hline
\end{tabular}

Source: Own estimation

TABLE 2

Error-correction form of the ration capital-labour, together with the co-integrating vectors

\begin{tabular}{lc}
\hline CO-INTEGRATING EQUATION: & Co-intEq1 \\
\hline LNRATIOCAL(-1) & 1.000000 \\
LNWAGINT(-1) & 0.123233 \\
& $(0.02505)$ \\
C & {$[4.91915]$} \\
ERROR CORRECTION: & -11.39462 \\
\hline Co-intEq1 & D(LNRATIOCAL) \\
& -0.099400 \\
& $(0.02197)$ \\
D(LNRATIOCAL(-1)) & {$[-4.52490]$} \\
& 0.179802 \\
D(LNWAGINT(-1)) & $(0.14757)$ \\
R-squared & {$[1.21845]$} \\
DAM. R-squared & -0.003780 \\
\hline & $(0.00748)$ \\
& {$[-0.50545]$} \\
& 0.011546 \\
& $(0.00427)$ \\
& {$[2.70441]$} \\
& -0.009163 \\
& $(0.00517)$ \\
& $0.927916]$ \\
& 0.916826 \\
\hline & \\
&
\end{tabular}

Note: t-statistics in bracket

Source: Own estimation

The various statistics provided in Table 1 reveal that the oneperiod lags level of the two variables is statistically significant. As the $99 \%$ critical value bounds for the F-distribution, under unrestricted intercept and restricted trend, is between 6.65 and 6.68 (bounds F-Critical), these values are associated with k-number of variables equal to two as in Appendix A. With the F-statistics of 52, clearly above the F-critical bounds, the null hypothesis is therefore rejected. This fact confirms the
TABLE 3

Error correction form of the ratio capital-labour with restriction of the cointegrating vecto

\begin{tabular}{|c|c|c|}
\hline CO-INTEGRATING EQUATION & C-intEq1 & \\
\hline LNRATIOCAL(-1) & 1.000000 & \\
\hline LNWAGINT(-1) & -1.000000 & \\
\hline C & -10.89202 & \\
\hline ERROR CORRECTION: & D(LNRATIOCAL) & D(LNWAGINT) \\
\hline \multirow[t]{3}{*}{ Co-intEq1 } & -0.000172 & 0.096276 \\
\hline & $(0.00321)$ & $(0.06338)$ \\
\hline & {$[-0.05356]$} & [1.51903] \\
\hline \multirow[t]{3}{*}{ D(LNRATIOCAL(-1)) } & 0.706233 & -2.111496 \\
\hline & $(0.13381)$ & $(2.64368)$ \\
\hline & [5.27785] & {$[-0.79870]$} \\
\hline \multirow[t]{3}{*}{$\mathrm{D}($ LNWAGINT(-1)) } & -0.012507 & -0.000189 \\
\hline & $(0.00977)$ & $(0.19305)$ \\
\hline & {$[-1.27997]$} & {$[-0.00098]$} \\
\hline \multirow[t]{3}{*}{ C } & 0.008854 & 0.059893 \\
\hline & $(0.00572)$ & $(0.11309)$ \\
\hline & [ 1.54676$]$ & [0.52962] \\
\hline \multirow[t]{3}{*}{ DAM } & -0.011164 & 0.085143 \\
\hline & $(0.00716)$ & $(0.14153)$ \\
\hline & {$[-1.55846]$} & {$[0.60158]$} \\
\hline R-squared & 0.871164 & 0.097183 \\
\hline Adj. R-squared & 0.851343 & -0.041712 \\
\hline Sum sq. resids & 0.002579 & 1.006825 \\
\hline S.E. equation & 0.009960 & 0.196784 \\
\hline F-statistic & 43.95179 & 0.699685 \\
\hline Log likelihood & 101.6228 & 9.134282 \\
\hline Akaike AIC & -6.233731 & -0.266728 \\
\hline Schwarz SC & -6.002443 & -0.035440 \\
\hline Mean dependent & 0.006918 & 0.095395 \\
\hline S.D. dependent & 0.025833 & 0.192804 \\
\hline
\end{tabular}

Note: t-statistics in bracket Source: Own estimation

existence of a long-term relationship between LNRATIOCAL and LNWAGINT.

Using the ARDL approach to the estimation of the long-term relationship between capital-labour ratio and price of capital and labour ratio, the following long-term relationship was estimated (see Table 2):

\section{LNRATIOCAL $=11.39-0.12$ LNWAGINT (4.91915)}

The above co-integrating equation, normalised for LNRATIOCAL with the t-statistic in brackets, shows that the elasticity of substitution is below unity. Its value equals 0.12 and it is statistically significant. The error-correction regression associated with the above long-term relationship is given in Table 2. It shows that the error term coefficient is estimated to be -0.09 , which is reasonably low, but highly significant. This in fact supports the hypothesis that there is a long-term relationship between LNRATIOCAL and LNWAGINT.

To test the hypothesis that $\sigma=1$, relating to the assumption of the Cobb Douglas function, a restriction of $(1,-1)$ was imposed on the co-integrating vector from the co-integrating relationship between LNWAGINT and LNRATIOCAL. The error-function, 
TABLE 4

Hyperparameters and final values of the state vector

\begin{tabular}{|c|c|c|c|c|}
\hline \multicolumn{5}{|c|}{ INCLUDED OBSERVATIONS: 36} \\
\hline \multicolumn{5}{|c|}{ CONVERGENCE ACHIEVED AFTER 8 ITERATION } \\
\hline & Coefficient & & & \\
\hline$C(1)$ & -5.951714 & & & \\
\hline$C(2)$ & -4104.135 & & & \\
\hline \multirow[t]{2}{*}{$C(3)$} & -34.01757 & & & \\
\hline & Final State & Root MSE & z-Statistic & Prob. \\
\hline SV1 & 2.272882 & 0.684544 & 3.320288 & 0.0009 \\
\hline sv2 & 0.780553 & 0.047603 & 16.39699 & 0.0000 \\
\hline
\end{tabular}

Source: Own estimation

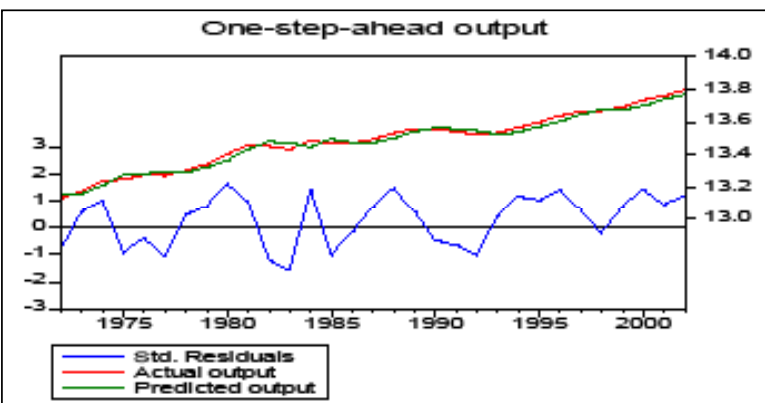

Note: Values of standard residuals, actual and predicted outputs are on the vertical axis. Years are represented on the horizontal axis

FIGURE 1

Dynamic fit of the production function (Source: Own construct)

a restriction of $(1,-1)$ was imposed on the co-integrating vector from the co-integrating relationship between LNWAGINT and LNRATIOCAL. The error-correction coefficient in Table 3 shows little evidence in support of the Cobb Douglas hypothesis given that the error-correction coefficient from the D(RATIOCAL) error-correction equation is not statistically significant.

\section{The estimation of the aggregate production function}

After theestimation of the equation representing the relationship between the average capital-labour ratio and the unit labour cost and capital-cost ratio, the second step consisted of estimating the relationship represented by equation $\log Q_{t}=\log A_{t}+\mu \log V_{t^{\prime}}$ which allowed the estimation of the aggregate production function. The estimation of this relationship necessitated the determination of the composite series as in equation $V_{t}=\left(\delta L_{t}^{-\rho}+(1-\delta) K_{t}^{-\rho}\right)^{\rho-\rho}$

Given the time series on the quantity of labour, capital and the estimation of the elasticity of substitution, and consequently the parameter of substitution, the composite series $\mathrm{V}$ was therefore computed. It must be noted that the average value of the distribution parameter, $\delta$, was obtained directly from the compensation of employees to GDP data, as published by Statistics South Africa, and not indirectly from equation LNRATIOCAL $=11.39-0.12$ LNWAGINT estimates. This was done in order to obtain estimates that were more accurate. The average value of $\delta$ amounted to $56 \%$.

$\mathrm{V}_{\mathrm{t}}$ is a composite series; its natural logarithm is represented as LNZEDt in equation LNGDPt $=\alpha_{t}+\mu_{t}$ LNZED $_{t}+\xi_{t}$. The series LNGDP represents the natural logarithm of GDP. $\alpha_{t}$ is the natural $\operatorname{logarithm}$ of $\mathrm{A}_{\mathrm{t}^{\prime}}$ as from equation $\log Q_{t}=\log A_{t}+\mu \log V_{t}$ Therefore, equation LNGDPt $=\alpha_{t}+\mu_{\mathrm{t}}$ LNZED $_{\mathrm{t}}+\xi_{\mathrm{t}}$ is a reformulated form of equation $\log Q_{t}=\log A_{t}+\mu \log V_{t}$.

The Kalman filter model in this study contains the following three equations:

$$
\begin{aligned}
& \text { LNGDPt }=\alpha_{t}+\mu_{t} \operatorname{LNZED~}_{t}+\xi_{t} \\
& \alpha_{t}=\alpha_{t-1}+\eta_{1 t} \\
& \mu_{t}=\mu_{t-1}+\eta_{2 t}
\end{aligned}
$$

Equation 3 is the measurement equation and equations 4 and 5 are transition or state equations. $\xi_{t^{\prime}} \eta_{1 t}$ and $\eta_{2 t}$ are error terms for the measurement and transition equations respectively. The state vectors are assumed to evolve through time according to a random walk process. Table 4 reports the estimation of the parameters of the Kalman filter model.

The specification equations, as in equations 3,4 and 5 , the results of which are reported in Table 4, are as follows:

\section{LNGDP $=$ SV1 + SV2 $*$ LNZED + [VAR=EXP(C (1))]}

SV1 $=$ SV1 (-1) $+[\operatorname{VAR}(C(2))]$

SV2 $=$ SV2 (-1) $+[\operatorname{VAR}(C(3))]$

SV1 represents the technological change state, while SV2 represents the scale of production state as specified in equations 4 and 5. The variances of the error terms of the measurement and states equations are the exponential function of $c(1), c(2)$ and c(3) respectively and they are presented in Table 4.

Figure 1 depicts the actual and forecast output obtained from the CES production function. The figure shows a good in-sample fit of the production function: this lends support for the use of the CES function as the best specification of the production function in South Africa.

The estimation of the relationship between education expenditure and technological change

The Granger causality test was conducted after confirming (from Figure 2) that the relationship between technological change and education and training expenditure can be fitted into a linear model.

If a variable $Z$ Granger-causes variable $Y$, then changes in $Z$ should precede changes in $Y$, according to the Granger causality test. It was important to determine whether education and training expenditure precedes or Granger-causes any change in technological change or total factor productivity to influence the rate of economic growth.

In determining whether Z Granger-causes $Y$, the following steps were followed in implementing the Granger causality test namely i) the current $Y$ was regressed on all lagged $Y$ terms and other variables with the exception of $Z$ (this is called a restricted regression and from this regression the restricted residual sum of squares, RSS $_{R}$ was obtained) ii) an unrestricted regression was run as in the first step (this time also including the lags of $\mathrm{Z}$ ) in order to obtain the unrestricted residual sum of squares, $\mathrm{RSS}_{\mathrm{UR}}$.

Futhermore, it was expected that $\mathrm{Z}$ does not Granger-cause $\mathrm{Y}$. That meant that lagged $Z$ terms were not the explanatory variables for $\mathrm{Y}$. To test this hypothesis, the F-test was applied:

$$
\mathrm{F}=\frac{\left(R S S_{R}-R S S_{E}\right) / m}{R S S_{K}(n-k)}
$$

The F-test follows the F-distribution with $\mathrm{m}$ and $(\mathrm{n}-\mathrm{k})$ of degree of freedom. If the computed F-value was to exceed the critical F-value at the chosen level of significance, the null hypothesis would have been rejected, in which case $Z$ does not cause $Y$.

The unrestricted regression is written as follows:

$$
\mathrm{Yt}=\sum_{i=1}^{n} \alpha_{i} Y_{t-i}+\sum_{j=1}^{n} \beta_{j} Z_{t-j}+\mu_{t} \quad \text { (Gujarati, 2003). }
$$




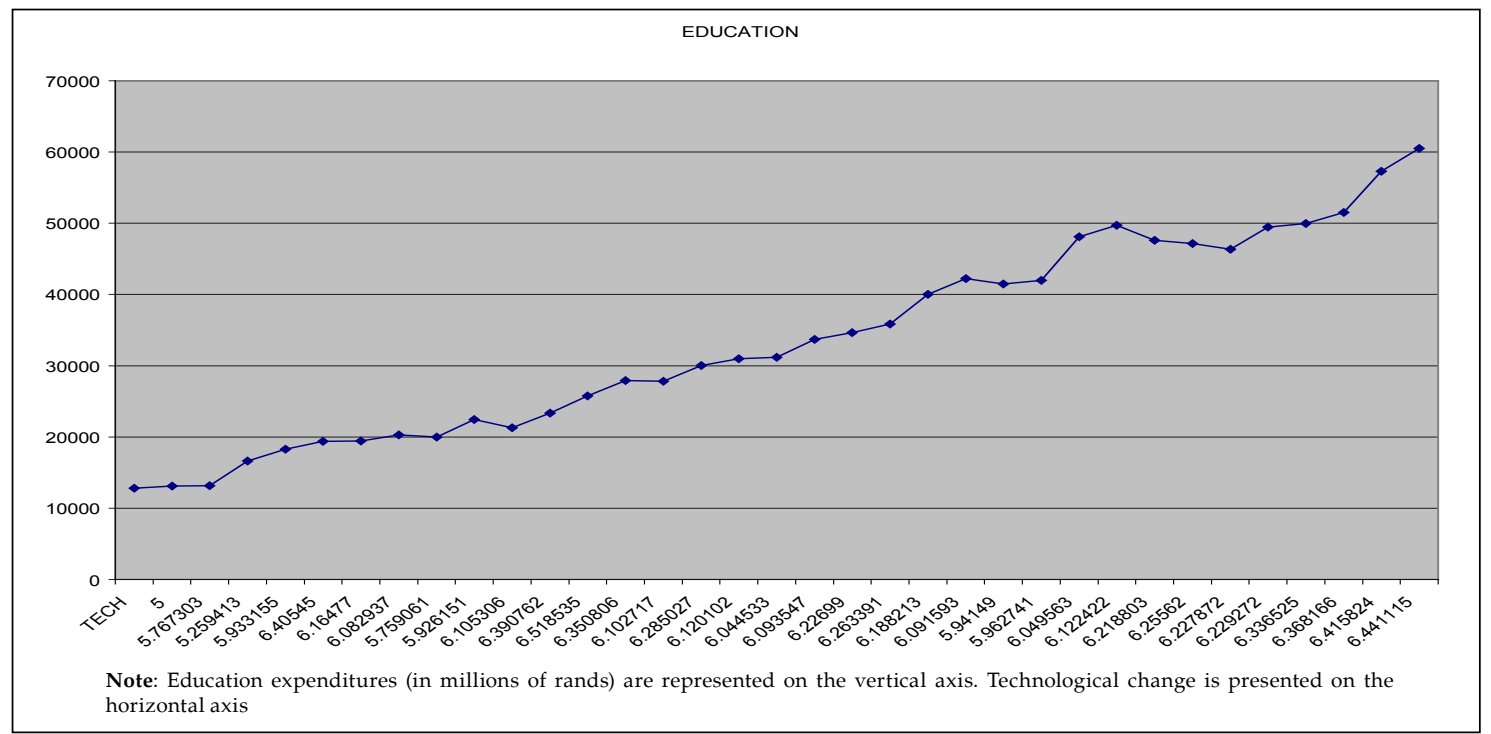

FIGURE 2

Relationship between education expenditure and technological change (Source: Own construct)

In a bivariate VAR describing the relationship between $Y_{t}$ and $Z_{t}, Z_{t}$ does not Granger-cause $Y_{t}$ if the coefficient matrices $\theta_{j}$ are lower triangular for all J:

$$
\begin{gathered}
{\left[\begin{array}{l}
Y_{t} \\
Z_{t}
\end{array}\right]=\left[\begin{array}{l}
c_{1} \\
c_{2}
\end{array}\right]+\left[\begin{array}{cc}
\theta_{1}^{(1)} & 0 \\
\theta_{1}^{(1)} & \theta_{2}^{(1)}
\end{array}\right]\left[\begin{array}{l}
Y_{t-1} \\
Z_{t-1}
\end{array}\right]+\left[\begin{array}{cc}
\theta_{1}^{(2)} & 0 \\
\theta_{1}^{(2)} & \theta_{2}^{(2)}
\end{array}\right]\left[\begin{array}{l}
Y_{t-2} \\
Z_{t-2}
\end{array}\right]+\ldots} \\
+\left[\begin{array}{cc}
\theta_{1}^{(p)} & 0 \\
\theta_{2}^{(p)} & \theta_{2}^{(p)}
\end{array}\right]\left[\begin{array}{l}
Y_{t-p} \\
Z_{t-p}
\end{array}\right]+\left[\begin{array}{l}
\varepsilon_{1 t} \\
\varepsilon_{2 t}
\end{array}\right]
\end{gathered}
$$

The above steps were followed to test whether education and training expenditure (the variable Education) Granger-causes technological change (the variable Tech) in the light of the endogenous growth theory. Two lags were used in Table 5 and five in Table 6 . The number of lags selected, for example five, indicates whether education expenditure incurred in the past five years affects the current level of technological change. Tables 5 and 6 show that the null-hypothesis (national education and training expenditure does Granger-cause technological change) is rejected. This does not support the view that the fiscal stimulus of human capital (more specifically the various annual national amounts spent on education and training) in South Africa translates into high technological change.

TABLE 5

Causality test between education expenditure and technological change

\begin{tabular}{llll}
\hline $\begin{array}{l}\text { PAIRWISE GRANGER CAUSALITY TESTS } \\
\text { SAMPLE: } 19712005\end{array}$ & & \\
\hline $\begin{array}{l}\text { Lags: } 2 \\
\text { Null Hypothesis: }\end{array}$ & Observations & F-Statistic & Probability \\
\hline $\begin{array}{l}\text { TECH does not granger-cause } \\
\text { EDUCATION }\end{array}$ & 33 & 0.14925 & 0.86204 \\
$\begin{array}{l}\text { EDUCATION does not granger- } \\
\text { cause TECH }\end{array}$ & & 0.34626 & 0.71031 \\
\hline
\end{tabular}

Source: Own calculation

TABLE 6

TABLE 6
Causality test between education expenditure and technological change

\begin{tabular}{llll}
\hline $\begin{array}{l}\text { PAIRWISE GRANGER CAUSALITY TESTS } \\
\text { SAMPLE: } 19712005\end{array}$ & & \\
\hline Lags: $\mathbf{5}$ & & & \\
\begin{tabular}{l} 
Null Hypothesis: \\
\hline $\begin{array}{l}\text { TECH does not granger-cause } \\
\text { EDUCATION }\end{array}$
\end{tabular} & Observations & F-Statistic & Probability \\
$\begin{array}{l}\text { EDUCATION does not granger- } \\
\text { cause TECH }\end{array}$ & & 0.58315 & 0.71262 \\
\hline
\end{tabular}

Source: Own calculation
This finding is quite important as it raises serious concern about the effectiveness of the fiscal stimulus of human capital (national government education and training expenditure) in South Africa. The poor performance of the return of the fiscal stimulus of human capital, which acts as a deterrent to high and sustainable economic growth in South Africa, may be explained by factors such as the inefficient structure of the education and training institutions, the small proportion of matriculants that pass mathematics, and so on.

\section{DISCUSSION}

The aim of the paper was to assess the relationship between fiscal expenditure on human capital and the efficiency of the human resource base in stimulating economic growth.

The null hypothesis that government expenditure on education and training does cause an increase in the level of technological change was rejected. The failure to prove the null hypothesis that education expenditure does Granger-cause technological changeindicated that there is an alarmingly poor return on national education and training expenditure in South Africa.

Possible reasons why the return on the national education and training expenditure is not significant in South Africa may include the misallocation of resources in education and training, the high drop out rate of pupils and the poor pass rate in mathematics and science subjects in grade 12 . These facts confirm the skills crisis that South Africa is currently experiencing. A follow-up study needs to be conducted on the finer details of the possible reasons why the fiscal stimulation of human capital does not render efficient and high returns for the South African economy.

\section{Recommendations}

Government expenditure on education and training should be more focussed. This entails closer cooperation with the private sector and other stakeholders in i) determining the problem employment areas (more specifically on skills development) and ii) the implementation of spending priorities.

\section{Limitations of the study}

The study simply focussed on government expenditure on education and training, and the effectiveness of the SETA structures were not part of the study. A follow-up study on the 
effectiveness of the SETA structures using the same econometric techniques would be a worthwhile academic exercise and the results of such a study will be beneficial to decision makers

\section{REFERENCES}

Alfonso, A. \& Werner, E. (2005). Quality of public finance and growth. Working paper series 438, European Central Bank.

Gujarati, D. (2003). Basic econometrics. (5th Ed.). New York: McGraw-Hill.

Gylfason, T. (1999). Principles of economic growth Oxford University Press: Oxford.

Harvey, A.C. (1989). Forecasting, Structural time series models and the Kalman Filter. Cambridge: University Press.

Nerlove, M. (1967). Recent empirical studies of the CES and related production function. In M. Brown (Ed.). The theory and empirical analysis of production, New York: NBER and Columbia University Press.

Pesaran, M.H., Shin, Y. \& Smith, R.J. (1999). Bounds testing approaches to the analysis of long-run relationships. Cambridge working paper in economics. University of Cambridge.

Ripatti, A. \& Vilmunen, J. (2001). Declining labour share evidence of a change in underlying production technology? Bank of Finland discussion paper 10/2001
Temple, J. (2000). Education and economic growth. Paper presented at the HM Treasury seminar on economic growth and government policy on 12 October 2000, United Kingdom.

Weil, D.N. (2005). Economic growth. New York: Pearson Education.

\section{APPENDIX A}

Critical Value Bound for the F- statistics, case with unrestricted intercept and no

\begin{tabular}{lllllll}
\multicolumn{7}{c}{ trend } \\
\hline $\mathrm{k}$ & $90 \%$ & & $95 \%$ & & $99 \%$ \\
0 & $\mathrm{I}(0)$ & $\mathrm{I}(1)$ & $\mathrm{I}(0)$ & $\mathrm{I}(1)$ & $\mathrm{I}(0)$ & $\mathrm{I}(1)$ \\
1 & 6.58 & 6.58 & 8.21 & 8.21 & 11.79 & 11.79 \\
2 & 4.04 & 4.78 & 4.94 & 5.73 & 6.84 & 7.84 \\
3 & 3.17 & 4.14 & 3.79 & 4.85 & 5.15 & 6.39 \\
4 & 2.72 & 3.77 & 3.23 & 4.35 & 4.29 & 5.61 \\
5 & 2.45 & 3.52 & 2.86 & 4.01 & 3.74 & 5.06 \\
6 & 2.26 & 3.35 & 2.62 & 3.79 & 3.41 & 4.68 \\
7 & 2.12 & 3.23 & 2.45 & 3.61 & 3.15 & 4.43 \\
\hline & 2.03 & 3.13 & 2.32 & 3.50 & 2.96 & 4.26 \\
\hline
\end{tabular}

Source: Pesaran, Shin and Smith (1999) 